\title{
Improving the performance characteristics of gas concrete impregnated with calcium polysulfide
}

\author{
Ismail A. Massalimov ${ }^{*}$ (D), Burhan I. Massalimov² (D), Akhat G. Mustafin ${ }^{1}$ \\ ${ }^{1}$ Bashkir State University, Ufa, Republic of Bashkortostan, Russia \\ ${ }^{2}$ The Lebedev Physical Institute of the Russian Academy of Sciences, Moscow, Russia \\ *Corresponding author: e-mail: ismail_mass@mail.ru
}

\begin{abstract}
Introduction. Impregnation with a solution based on calcium polysulfide showed excellent results in the hydrophobization of concrete, brick and shell rock due to the formation of a water-repellent coating of sulfur nanoparticles on the surface of their pores. This paper presents the data of studying the properties of aerated concrete, widespread in construction practice, which has a widely developed pore system. Materials and methods. The data on the penetration of water into the studied samples of aerated concrete using the methods of visual examination, including electron microscopy, as well as methods for measuring the water absorption and strength of the samples impregnated with a solution based on calcium polysulfide are presented. Results. It is shown that aerated concrete impregnated with calcium polysulfide, despite the developed pore system, acquires pronounced water-repellent properties. It was found that the optimal processing time is 20 minutes, and the increase in the water-repellent properties of aerated concrete depends on the density of the impregnating solution. As a result of impregnation of aerated concrete by immersion in a solution with a density of $1.16 \mathrm{~g} / \mathrm{cm}^{3}$, a decrease in 3.7 times occurs, and when treated with a solution with a density of $1.25 \mathrm{~g} / \mathrm{cm}^{3}$, it decreases 6.8 times and becomes equal to $6 \%$. For samples processed with the use of vacuum, in the case of processing a solution with a density of $1.16 \mathrm{~g} / \mathrm{cm}^{3}$, water absorption decreases by 7.9 times, and when processing with a solution using vacuum, it decreases 19.8 times, while the compressive strength increases by 1.7 once. Samples of aerated concrete, treated with a polysulfide-based solution with a brush, showed that in this case, water absorption in the sprinkling mode decreases to values of $1.5-2.0 \%$. Discussion. It is noted that during the surface treatment of aerated concrete, a chemically resistant, water-repellent layer 3-3.5 cm thick is formed, which reliably protects the material from the penetration of water and chemicals. The results of the performed experiments give reason to believe that on the surface of the pores of aerated concrete treated with a solution based on calcium polysulfide, as well as on the surface of the pores of previously investigated materials, a nanosized coating is formed of sulfur particles that hydrophobic aerated concrete. Conclusions. Comparison of the results for aerated concrete with excellent data for concrete, brick, shell rock shows that the efficiency for aerated concrete is no less and allows us to recommend the specified solution for long-term protection of the surface of aerated concrete walls.
\end{abstract}

KEYWORDS: sulfur, nanoparticle, aerated concrete, water absorption, strength, hydrophobicity, protective coating.

FOR CITATION: Massalimov I.A., Massalimov B.I., Mustafin A.G. Improving the performance characteristics of gas concrete impregnated with calcium polysulfide. Nanotechnologies in Construction. 2021;13(6): 343-349. https://doi.org/10.15828/2075-8545-202113-6-343-349.

\section{INTRODUCTION}

$\mathrm{T}$ he main reason for the degradation of porous building structures is the atmospheric-chemical factor. The use of protective coatings makes it possible to increase the durability of buildings and structures by reducing the amount of water penetrating into the pores, but the main problem in this area is the service life of the coating itself, especially under conditions of constant exposure to water and sign-changing temperatures. The problem of long-term protection of concrete structures exposed to intense exposure to moisture and groundwater has not yet been resolved - the available deep penetration impregnating compositions are quite expensive and cannot be effectively used in all the cases. In this regard, it is urgent to search for a new effective and convenient method of long-term protection of building structures and products using various methods [1-2]. One of the methods of protection is based on the creation of a water-repellent effect in building materials by the use of impregnation

(c) Massalimov I.A., Massalimov B.I., Mustafin A.G., 2021 
with sulfur melt [3-4], however, the application of the method is limited by the complexity of use associated with obtaining a melt and the need for evacuation.

In works [5-8], a new method is proposed that allows increasing the durability of buildings and structures by reducing the amount of water penetrating into the pores. The developed impregnating composition based on sulfur provides protection of building materials from weathering and corrosive environments for a long time. The technology for processing structural elements and products is simple and affordable: like most paints and varnishes, they are applied with a brush, pouring, spraying, dipping at any positive temperatures. The fundamental novelty of the proposed solution lies in the fact that hydrophobization is achieved using a material of inorganic nature - sulfur. The presence of sulfur in the pores of building materials gives them waterrepellent properties for a long time - in contrast to organic paints and varnishes. The uniqueness of the approach lies in the fact that at the stage of impregnation a water-soluble substance is used, within which sulfur molecules fall into the smallest pores of the material.

During the drying stage this substance decomposes and a water-insoluble (hydrophobic) layer of elemental sulfur is formed on the surface of the pores. At the drying stage, this substance decomposes and a water-insoluble (hydrophobic) layer of elemental sulfur nanoparticles is formed on the pore surface. The use of deep impregnation allows, along with an increase in strength and frost resistance, a decrease in water absorption, to significantly increase resistance to atmospheric factors, chemical resistance to acids, saline solutions, oil products. The mineral nature of the coating, formed from sulfur nanoparticles, ensures its durability, and the water-repellent properties inherent in elemental sulfur blocks the access of water. The surfaces treated with the proposed composition acquire not only hydrophobic properties, but also pronounced bactericidal properties, as a result, the processes of decay and mold formation are prevented.

This method improves the mechanical characteristics of building structures (piles, bridges, floor arches, tunnels, trays, culverts, wells, sidewalk and road slabs, curb stones, etc.) operating in conditions of atmospheric factors and groundwater. The method of hydrophobization with polysulfide solutions is also protected by a Russian and Eurasian patent $[9,11]$. Currently, the method has become widespread and is used to strengthen wells [12-14].

At the same time, there are other building materials (foam concrete, aerated concrete, wood, etc.), which also need long-term and reliable protection from atmospheric factors. For this purpose, aerated concrete was investigated, which has a developed porous structure and is exposed to water. Autoclaved aerated concrete is one of the most popular building materials used in the construction of individual houses. It is popular due to its excellent consumer properties: low thermal conductivity and environmental friendliness. But at the same time aerated concrete is characterized by a high value of water absorption (30-50\%) and relatively low values of compressive strength, which significantly limits its use. This material is also popular abroad, work is underway to obtain materials and methods for protecting aerated concrete [15-22]. In this work, a composition based on calcium polysulfide was used to modify the properties of aerated concrete; the latter was impregnated with the material and its properties were studied.

\section{METHODS AND MATERIALS}

To carry out the work, a solution based on calcium polysulfide (calcium pentasulfide CaS5) with different densities in the range from $1.16 \mathrm{~g} / \mathrm{cm}^{3}$ to $1.25 \mathrm{~g} / \mathrm{cm}^{3}$ was used, and aerated concrete with a density of $0.547 \mathrm{~g} / \mathrm{cm}^{3}$ with dimensions of $16 \times 4 \times 4 \mathrm{~cm}$ was used as samples. Since aerated concrete is mainly used as a wall material, it was processed with a brush, in addition, it was also tested by immersing the samples in a solution based on calcium polysulfide. The impregnation of aerated concrete samples was carried out by completely immersing them in a bath with a polysulfide solution so that the solution level exceeded the level of the upper edge of the samples by at least $5 \mathrm{~cm}$. The impregnation of aerated concrete samples was carried out with various durations (from 10 to 80 minutes) 20 minutes.

Water absorption measurements were carried out according to the method described in GOST 12730.32020. Determination of water absorption with preliminary evacuation of the samples was carried out in a chamber from which air was evacuated and an impregnating solution was supplied until the samples were completely covered with the solution. The strength measurements of the initial and impregnated samples were carried out in accordance with GOST 10180-2012. The depth of penetration of the impregnating solution into the depth was checked by analyzing sections of freshly impregnated samples. The analysis of the size of sulfur nanoparticles and the distribution of the hydrophobizing material in the pores was carried out by Shimadzu Wing SALD-7071 and an AXIOVERT.A1 microscope.

\section{RESULTS}

Since aerated concrete, like most building materials, is an inorganic material and is wetted with water, and gradually water fills the pores of aerated concrete (Fig. 1a). Treatment with a solution based on calcium polysulfide leads to the coloring of aerated concrete in a light green color, in addition, the appearance of sulfur nanoparticles on the surface of aerated concrete leads to the appearance of water-repellent properties (Fig. 1b), a drop of water on the surface of the sample is not absorbed. 

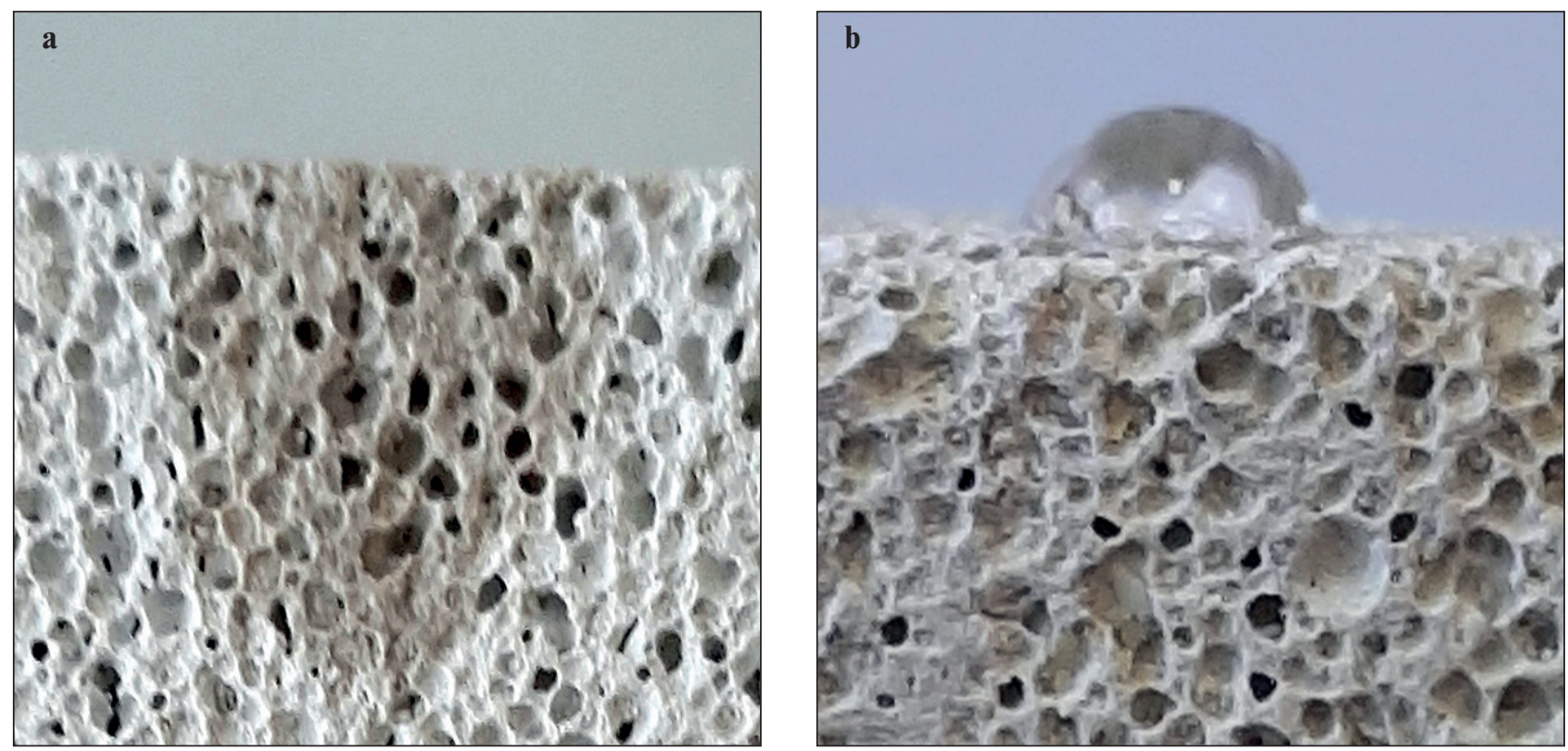

Fig. 1. The appearance of aerated concrete: $a-$ untreated; $b$ - processed

The samples were processed by immersion in a solution based on calcium polysulfide of various densities for 1 hour; the results are shown in Fig. 2. The water absorption of the original non-impregnated samples was $35.6 \%$. The data presented in Fig. 3 show that water absorption decreases when using a solution with a density equal to $1.16 \mathrm{~g} / \mathrm{cm}^{3}$, water absorption decreases by 3.7 times, and when treated with a solution with a density of 1.25 it decreases by 6.8 times. For samples processed with the use of evacuation, in the case of processing a solution with a density of $1.16 \mathrm{~g} / \mathrm{cm}^{3}$, water absorption decreases by 7.9 times, and when processing with a solution with a density of 1.25 , it decreases 19.8 times. Thus, a solution based on calcium polysulfide effectively hydrophobizes aerated concrete and can be used to protect structures made of this material. For example, the walls of low-rise buildings that have water-repellent properties can be laid out of aerated concrete blocks.

Samples impregnated under vacuum with different duration of keeping in solution were tested for compressive strength (Fig. 3). The data on the dependence of the strength on the residence time in the solution show that the residence time in the solution equal to 20 minutes is sufficient for the solution to be absorbed. The results

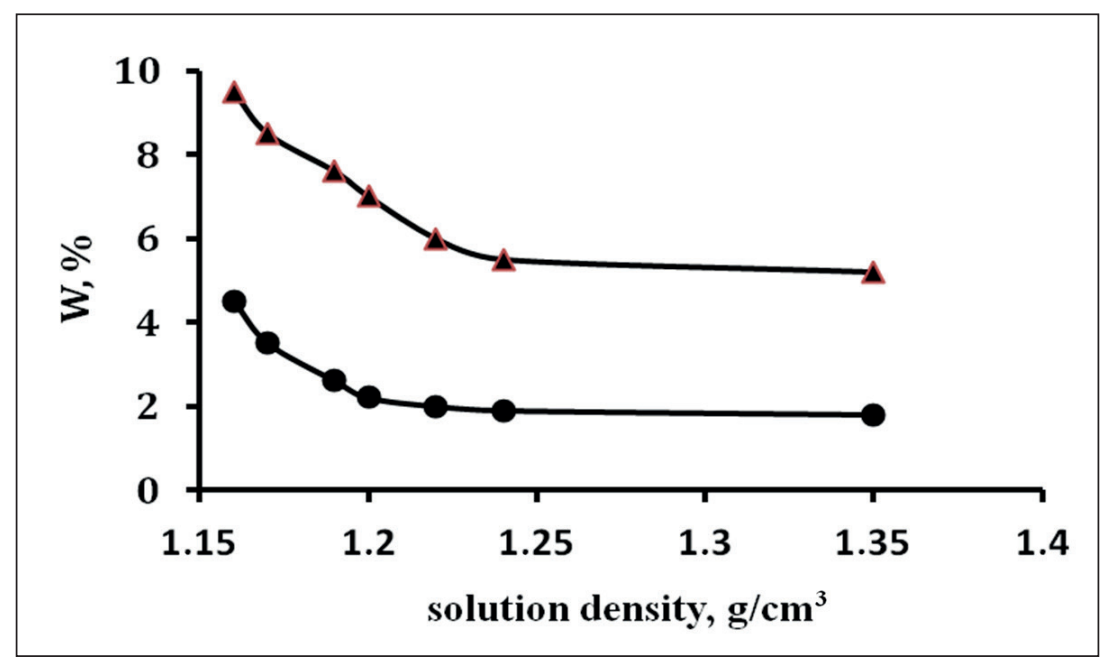

Fig. 2. Water absorption of aerated concrete samples impregnated by immersion in a solution based on calcium polysulfide of various densities at atmospheric pressure $(\Delta)$ and using vacuum $(\bullet)$ 


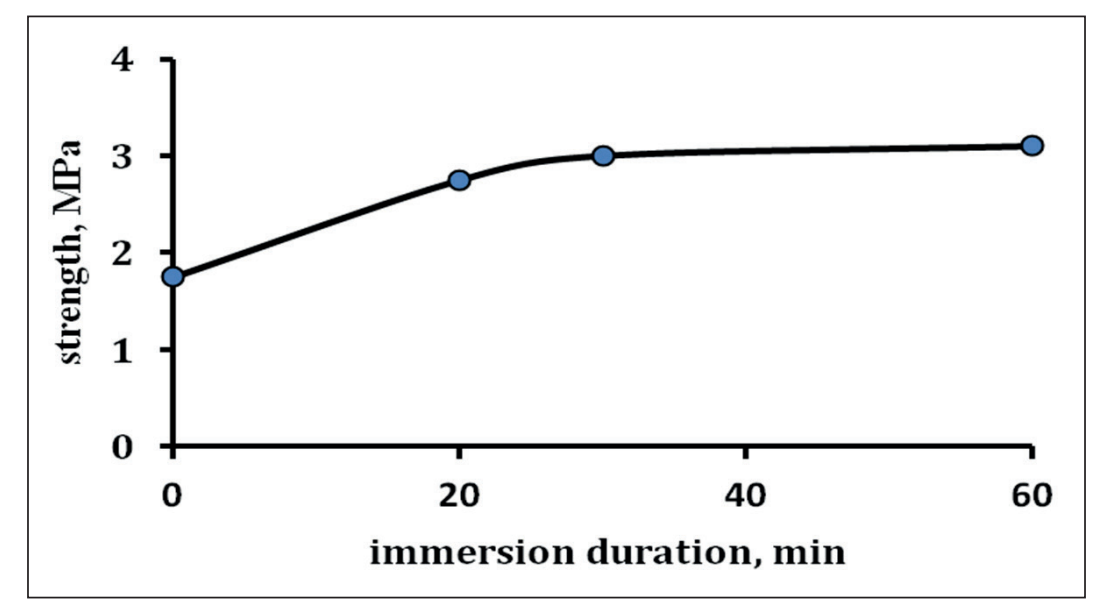

Fig. 3. Dependence of the compressive strength of aerated concrete samples impregnated by immersion in a solution based on calcium polysulfide on the duration of holding in the solution

show an increase in compressive strength from 1.75 $\mathrm{MPa}$ to $3 \mathrm{MPa}$ when held in solution for more than 20 minutes; further holding does not lead to a noticeable increase in strength.

Since the main application of aerated concrete is supposed to be the protection of walls that are exposed to moisture in the sprinkling mode, the samples were repeatedly brushed and dried under natural conditions. The processing was carried out as follows. Repeated brush strokes were applied layer by layer until the solution was absorbed by the aerated concrete. Then, after it was absorbed, but not dried, a second layer was applied in the same way. Then the process was repeated a third time. Figure 4 shows sections of dried samples after three brush treatments; it can be seen that the solution applied with a brush successively penetrates into the depth of the sample. The treatment was carried out with a solution with a density equal to $1.24 \mathrm{~g} / \mathrm{cm}^{3}$. The results showed that after passing the hand three times, the penetration depth exceeds $2 \mathrm{~cm}$.

Samples treated with a brush were tested for water absorption, for this purpose they were processed in the spray mode. For this purpose, the samples were exposed to water droplets in a similar manner to rainfall for 1 hour. It was found that water absorption does not exceed 1.5$2.0 \%$ for those treated three times with a brush (Fig. 5). Thus, brushing or spraying a solution based on calcium polysulfide on a wall lined with aerated concrete can protect the material from water penetration, even without using additional protection measures, by applying plaster or other water repellents to the wall.

Samples soaked in a solution of calcium polysulfide were examined by direct observation in reflected light on an AXIOVERT.A1 microscope. Figure 6 shows the mi-

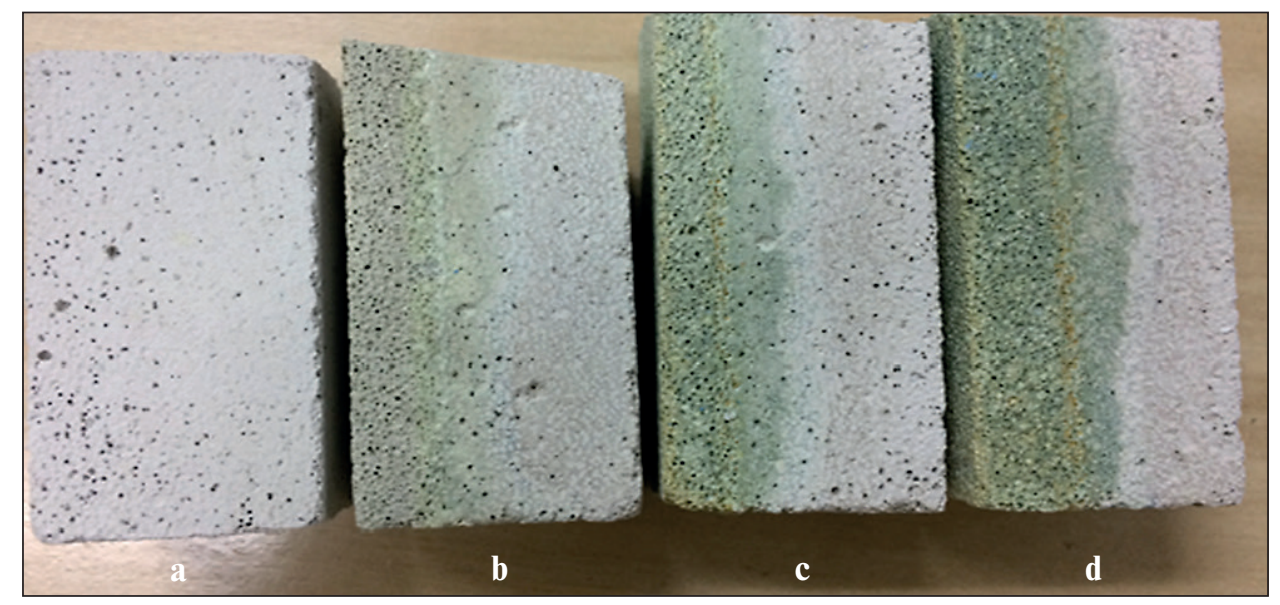

Fig. 4. Samples of aerated concrete cut impregnated with a solution based on calcium polysulphide with a density equal to $1.24 \mathrm{~g} / \mathrm{cm}^{3}$ : a) initial non-impregnated; b) processing with a single pass of the brush; c) processing with a double pass of the brush; d) processing by three passes of the brush 


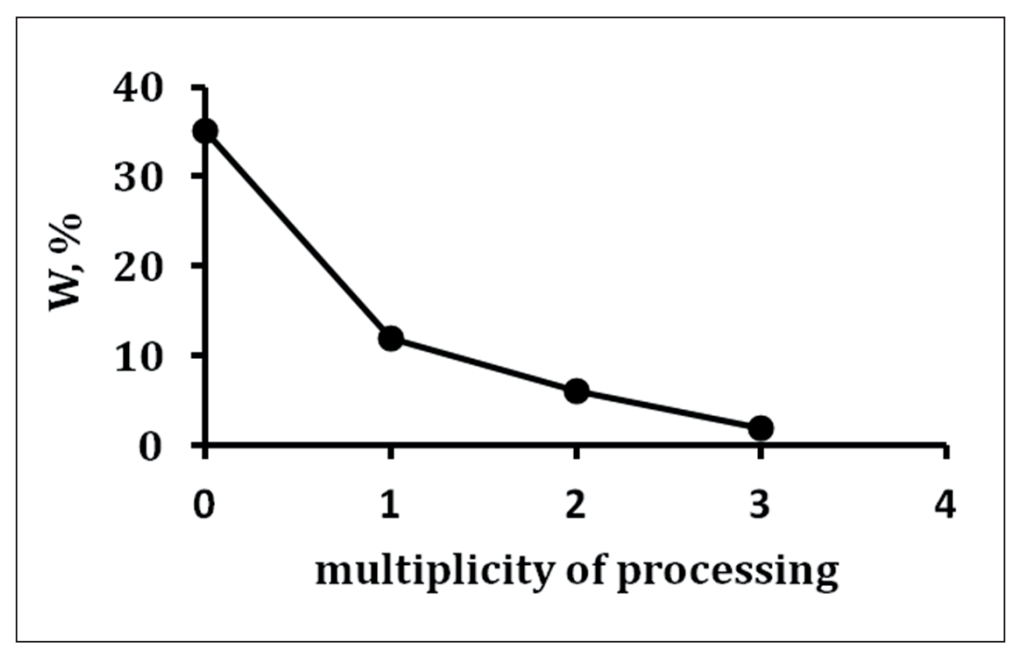

Fig. 5. Dependence of water absorption of aerated concrete under sprinkling conditions, depending on the frequency of treatment

crostructure of aerated concrete samples impregnated with polysulfide solutions. From Figure 6 it can be seen that the voids between the grains of aerated concrete are filled with a composite of sulfur nanoparticles and calcium carbonate, as a result, the compressive strength increases (Fig. 3) and water absorption decreases (Fig. 6).

\section{DISCUSSION}

The data obtained in the work show that aerated concrete is successfully hydrophobized by impregnation with a solution based on calcium polysulfide, despite the fact that it has a well-developed pore system, that is, there are many voids inside aerated concrete. To find out at the expense of which particles the aerated concrete is hydrophobized from the polysulfide solution, after impregnation and drying, particles were separated from the pore space

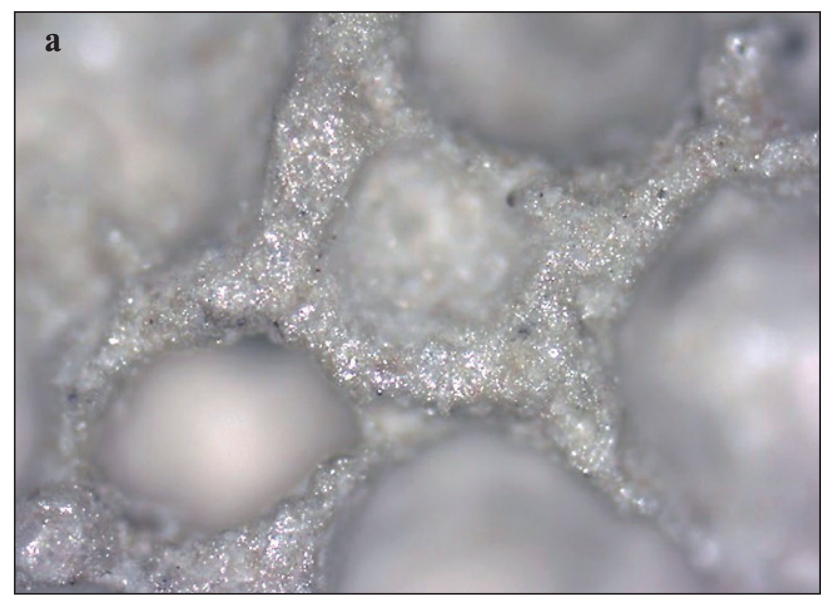

of the material. For this, the impregnated sample of aerated concrete was dried and dissolved in a solution of hydrochloric acid. The dispersed powder that precipitated was washed with distilled water and dried, then the coarse fraction was separated from the fine fraction in a centrifuge. Then the fine fraction was analyzed using a laser analyzer, as a result, differential and integral distributions of the sizes of sediment particles were obtained, similar to those in ([8], Fig. 2). They showed that the average particle size is $20 \mathrm{~nm}$, and $\mathrm{X}$-ray phase analysis showed that the particles are elemental sulfur with an orthorhombic crystal lattice structure similar to the results ([8], Fig. 3).

The impregnating solution in this case is a carrier of a hydrophobizing agent (sulfur nanoparticles), which in the composition of calcium polysulfide molecules, the size of which does not exceed $0.5 \mathrm{~nm}$, easily penetrates not only into the pores, but also into the smallest capillary

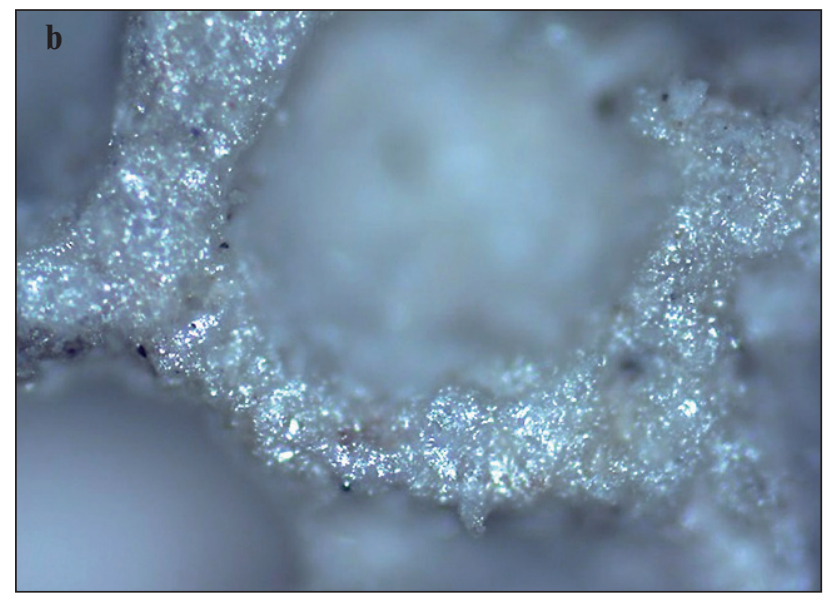

Fig. 6. Image of the pore space of aerated concrete impregnated with a polysulfide solution: $\mathrm{a}-$ an increase of 500 times; $\mathrm{b}$ - an increase of 1000 times 
tracts of aerated concrete. At the drying stage, the calcium polysulfide molecule is destroyed, and sulfur nanoparticles are formed, which are hydrophobic by their chemical nature. Microscope data (Fig. 6) show how nanoparticles crystallized from a polysulfide solution at the stage of aerated concrete drying form a protective coating in the pore structure, taking up free space in the pores.

Due to the low viscosity, the impregnating solution easily penetrates deep into the material, if applied with a brush, it penetrates to a depth of 3-3.5 cm (Fig. 4), when immersed in the solution, it can completely impregnate the sample, reduce it from $35.6 \%$ to a value equal to $5 \%$, and in the case of vacuumization, it reduces water absorption to $2 \%$ (Fig. 2). The fact that this material is excellently hydrophobized by a polysulfide solution can be seen with the naked eye: for an untreated sample, water immediately penetrates deep into the material, and in a processed sample it lies in the form of a spherical drop until it evaporates (Fig. 1). The data on water absorption are comparable with the corresponding data for shell rock 2-3\% [7, 8], concrete $0.5-2.5 \%$ [6, 15], brick 4-5\% [5]. An improvement in the parameters of water absorption and strength, as well as a slight change in color (acquiring a weak green color) when modifying aerated concrete with a polysulfide solution, make it possible to hope that this method of hydrophobization will be widely used. The presented data on the penetration of water into the studied samples of aerated concrete shows that the method of improving the properties of aerated concrete by impregnating samples with a solution based on calcium polysulfide works excellently in this case and can be recommended for use in low-rise construction of cottages, as well as when using aerated concrete as a material for internal partitions of buildings.

\section{CONCLUSIONS}

1. Treatment of aerated concrete with a solution based on calcium polysulfide demonstrates that a pronounced hydrophobic effect is observed (see Fig. 1).

2. Impregnation of aerated concrete samples with a solution based on calcium polysulfide showed that with an increase in the density of the solution, the efficiency of impregnation increases to density values equal to $1.25 \mathrm{~g} / \mathrm{cm}^{3}$, treatment at atmospheric pressure reduces water absorption by 6.8 times, and when using a solution of calcium polysulfide water absorption is reduced by 7.9 times, and when treated with a solution of calcium polysulfide with the use of evacuation, it is reduced by 19.8 times.

3. Water absorption of the original aerated concrete equal to $35 \%$ decreases as a result of surface treatment with a solution based on calcium polysulfide to water absorption of $1.5-2.0 \%$ in the sprinkling mode, which allows using aerated concrete for laying walls without additional hydrophobization (Fig. 5).

4. Studies on the AXIOVERT.A1 microscope (Fig. 6) made it possible to find out that after impregnation of aerated concrete, its pores are filled with hydrophobic sulfur, which causes a water-repellent effect and an increase in strength.

5. As a result of the experiments, it was found that the effect of hydrophobization of aerated concrete is achieved due to the formation of a nanoscale coating consisting of sulfur nanoparticles with a size of $20 \mathrm{~nm}$, which is formed during the transformation of calcium polysulfide into hydrophobic sulfur particles, as a result, significantly reduces water absorption, which leads to an increase in durability.

\section{REFERENCES}

1. Bazhenov Yu.M. Concrete polymers. Moscow: Stroyizdat; 1983.

2.Pokrovsky N.S. Concrete impregnating waterproofing. Moscow: Energy; 1964.

3.Ramachandran V., Feldman R., Baudouin J. Concrete Science. Physicochemical Concrete Science. Concrete science: treatise on current research. London: 1981.

4. Paturoev V.V., Volgushev A.N. The main characteristics of concrete impregnated with sulfur. Moscow: TsINIS Gosstroy USSR; 1976.

5. Massalimov I.A., Yanakhmetov M.R., Chuykin A.E., Mustafin A.G. Protection of Building Constructions with Sulfur Impregnating Solution. Study of Civil Engineering and Architecture (SCEA). 2013; 2(2): 19-24. Available from: https://www. researchgate.net/publication/287432901 [Accessed $5^{\text {th }}$ November 2021].

6. Massalimov I.A., Yanahmetov M.R., Chuykin A.E. Strength and durability of concrete, modified impregnating composition based on sulfur. Nanotechnologies in Construction. 2015; 7(3): 61-75. Available from: http://www. nanobuild.ru/en_EN/journal/Nanobuild-3-2015/61-75.pdf [Accessed $5^{\text {th }}$ November 2021].

7. Massalimov I.A., Massalimov B.I., Akhmetshin B.S., Urakaev F.Kh., Burkitbaev M.M. Improving the operational characteristics of wastes from the extraction of shell limestone by impregnation with polysulfide solutions. Nanotechnologies in Construction. 2020; 12(2): 77-83. https://doi.org/10.15828/2075-8545-2020-12-2-77-83. 
8. Massalimov I.A., Chuikin A.E., Massalimov B.I., Urakaev F.Kh., Uralbekov B.M., Burkitbaev M.M. Improvement of the operational properties of building materials from limestone-shell rock by impregnation with polysulfide solutions. Nanotechnologies in Construction. 2017; 9(3): 66-80. https://doi.org/10.15828/2075-8545-2017-9-3-66-80.

9. Massalimov I.A., Babkov V.V., Mustafin A.G. Composition for processing buil-ding materials and method of their processing. RF Patent 2416589. 2009-09-23.

10. Massalimov I.A., Yanakhmetov R.R., Chuikin A.E., Khusainov A.N., Mustafin A.G. Method of processing building materials with polysulfide solutions. Eurasian Patent 024383. 2016-09-30.

11. Galiakhmetov R.N., Massalimov I.A., Mustafin A.G. Wood protection method. RF Patent 2481944. 2011-10-17.

12. Agzamov F.A., Tokunova E.F., Sabirzianov R.R. The application of calcium polysulfide to increase corrosion resistance of the timbering of wells. Nanotechnologies in Construction. 2019; 11(3): 308-324. DOI: 10.15828/20758545-2019-11-3-308-324.

13. Sabirzyanov R.R. Improvement of the quality of plugging stone in corrosive environments. In: 75 Years of Oil Education in the Republic of Bashkortostan: Abstracts of All-Russian Scientific and Technical Conf., dedicated to the $70^{\text {th }}$ anniversary of USPTU, 29 November 2018, Ufa. Ufa: 2018. p. 53.

14. Agzamov F.A., Sabirzyanov R.R., Karimov I.N. Backfill material. RF Patent 2717317. 2019-06-14

15. Massalimov I.A., Ianakhmetov, Chuykin A.E., Massalimov B.I., Urakaev F.H., Uralbekov B.M., Burkitbaev M.M. Hydrophobization of dense and fine concrete by polysulfide solutions. Nanotechnologies in Construction. 2016; 8(5): 85-99. DOI: 10.15828/2075-8545-2016-8-5-85-99.

16. Struharova A. Chemical grouting method and its effectiveness for protection of autoclaved aerated concrete masonry. Advanced Materials Research. 2014; 923: 112-116. https://doi.org/10.4028/www.scientific.net/AMR.923.112

17. Xue Li Jin, Xiang Yu Luo, Qing Lin Meng. Effect of equilibrium moisture contents on insulating performance of autoclaved aerated concrete blocks. Advanced Materials Research. 2011; 216: 479-484.

18. Fenglan Li, Gonglian Chen, Yunyun Zhang, Yongchang Hao, Zhengkai Si. Fundamental properties and thermal transferability of masonry built by autoclaved aerated concrete self-insulation blocks. Materials (Basel). 2020: 13(7): p.1680. DOI: $10.3390 / \mathrm{ma} 13071680$

19. Narayanan N., Ramamurthy K. Structure and properties of aerated concrete: a review. Cement \& Concrete Composites. 2000; 22: 321-329.

20. Suleimanova L. A., Lesovik V. S. Aerated concrete of non-autoclave hardening on composite binders. Belgorod: Publishing house BSTU; 2013.

21. Ahmed Ash, Kamau John. Sustainable construction using autoclaved aerated concrete (aircrete) blocks. Res Dev Material Sci. 1(4). RDMS.000518. 2017. DOI: 10.31031/RDMS.2017.01.000518

22. Masodkar S.P. Vasatkar A.R. A study on properties of autoclaved aerated concrete for feasibility in construction. International journal of innovative research in technology. 2018; 5(7): 373-377.

\section{INFORMATION ABOUT THE AUTHORS}

Ismail A. Massalimov - Dr. Sci. (Eng.),Professor, Bashkir State University (BashSU), Ufa, Bashkortostan Republic, Russia, ismail_mass@ mail.ru, https://orcid.org/0000-0002-4789-9469

Burhan I. Massalimov - Junior researcher, the Lebedev Physical Institute of the Russian Academy of Sciences, Russian Academy of Sciences, Moscow, Russia, b.massalimov@yandex.ru, https://orcid.org/0000-0003-2456-5113

Akhat G. Mustafin - Dr. Sci. (Chem.), Professor, Bashkir State University (BashSU), Ufa, Bashkortostan Republic, Russia, agmustafin@ gmail.com, https://orcid.org/0000-0002-8342-8787

\section{CONTRIBUTION OF THE AUTHORS}

Massalimov I.A. - conceived the idea, collected and processed necessary material, wrote the manuscipt.

Massalimov B.I. - performed measurements with microscope and measurements of water absorption.

Mustafin A.G. - collected relevant data, edited the manuscript and prepared final version of the publication.

\section{The authors declare no conflicts of interests.}

The article was submitted 05.10.2021; approved after reviewing 30.10.2021; accepted for publication 03.11.2021. 